\title{
High-directivity Antenna for Low-UWB Body Area Networks Applications
}

\author{
Chaïmaâ Kissi \\ Electronics and Telecommunication \\ Systems Research Group, National \\ School of Applied Sciences (ENSA), \\ Ibn Tofail University \\ Kenitra, Morocco \\ chaimaakissi1@gmail.com
}

Marko Sonkki

Center for Wireless Communications,

Faculty of Information Technology and

Electrical Engineering,

University of Oulu

Oulu, Finland

$\underline{\text { marko.sonkki@oulu.fi }}$

\author{
Mariella Särestöniemi \\ Center for Wireless Communications, \\ Faculty of Information Technology and \\ Electrical Engineering, \\ University of Oulu \\ Oulu, Finland \\ mariella.sarestoniemi@oulu.fi \\ Sami Myllymäki \\ Microelectronics Research Unit, \\ Faculty of Information Technology and \\ Electrical Engineering, \\ University of Oulu \\ Oulu, Finland \\ sami.myllymaki@oulu.fi \\ Heli Jantunen \\ Microelectronics Research Unit, \\ Faculty of Information Technology and \\ Electrical Engineering, \\ University of Oulu \\ Oulu, Finland \\ heli.jantunen@oulu.fi
}

\author{
Carlos Pomalaza-Raez \\ Department of Electrical and Computer \\ Engineering, \\ Purdue University \\ Fort Wayne, Indiana 46805, USA \\ cpomalaz@purdue.edu
}

Mohamed Nabil Srifi

Electronics and Telecommunication

Systems Research Group, National

School of Applied Sciences (ENSA),

Ibn Tofail University

Kenitra, Morocco

srifimn@gmail.com

\begin{abstract}
Novel antenna operating at the Low-UWB band BAN (Body Area Network) is presented in this paper. Basically, the antenna offers an omnidirectional radiation pattern without the cavity presence. However, the proposed antenna changes the radiation behavior to directional radiation pattern with $5.5 \mathrm{dBi}$ increase in gain by introducing an air cavity. The antenna performances were assessed in free-space and simulations were carried out by CST Microwave Studio software. The detailed antenna study shows that the proposed antenna could be considered a good on-body antenna for LowUWB applications, in particular for Wireless Capsule Endoscopy (WCE) localization.
\end{abstract}

Keywords-High gain, directional radiation pattern, omnidirectional radiation pattern, Low-UWB band, Wireless Capsule Endoscopy localization, WCE.

\section{INTRODUCTION}

Last years, UWB antennas have gained more attention because of its wide range use in several applications. These antennas are strongly present in wireless communications, radar sensing, receiver systems [1-3], etc. However, nowadays new technologies tend towards Low-UWB band, for example for WCE (Wireless Capsule Endoscopy) systems and particularly for capsule localization approaches [4-5]. This frequency range attracts more researcher focus especially for clinical use, where high image resolution is the main exigency. Besides that, the presence of the human body requests the use of lower UWB frequencies so as to mitigate the path losses in the communication link [5]. A vigilant research for WCE localization systems and approaches shows the unavailability of receiving antennas working at Low-UWB Band (IEEE 802.15.6 standard) [6] designed for WCE localization purposes. It is well known that, receiving antennas answer to some requirements, mainly the good directivity. In this perspective, various approaches are involved like the cavity approach known by guaranteeing good directivity besides high gain [7-18].

The present paper proposes a novel Low-UWB directional antenna achieving high gain and in compliance with IEEE 802.15.6 standard for BAN (Body Area Networks). The antenna is not restricted only to radar applications, but can be also a good receiving on-body antenna useful for WCE (Wireless Capsule Endoscopy) localization scenario. Comparing the proposed antenna to the new available UWB antennas [19], it is clearly resulted that the proposed directional antenna has good performances. The paper is organized as following: Section II brings the overall antenna structure, Section III presents the antenna study and analysis, and finally Section IV provides a conclusion and the work perspectives.

\section{ANTENNA STRUCTURE}

The proposed Low-UWB planar monopole antenna is printed on one side of FR-4 material $\left(\varepsilon_{r}=4.3\right)$ with $1.6 \mathrm{~mm}$ thickness (hs), as illustrated in Fig. 1. The antenna is fed by a $50 \Omega$ Coplanar Waveguide (CPW). The width (W4) and length (L2+L3) of the transmission line is 2 and $10.8 \mathrm{~mm}$, respectively. The gap (W3) between the feed line and the ground plane is $0.25 \mathrm{~mm}$. The radiating element form of the antenna is constituted of a rectangle and a halfcircle shape (of radius $\mathrm{R}$ ) combination. The antenna overall size is $36 \times 34 \times 1.6 \mathrm{~mm}^{3}$. Detailed optimized parameters of the proposed UWB antenna is summarized in Table I. 


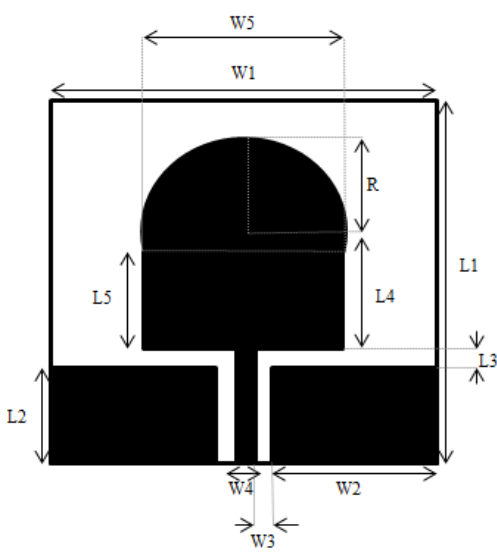

Fig. 1. Geometry of the proposed Low-UWB planar monopole antenna.

TABLE I. OPTIMIZED PARAMETERS OF THE PROPOSED LOWUWB ANTENNA

\begin{tabular}{ccccccc}
\hline Parameter & hs & R & W1 & W2 & W3 & W4 \\
\hline Value $(\mathrm{mm})$ & 1.6 & 11 & 36 & 17.5 & 0.25 & 2 \\
\hline Parameter & W5 & L1 & L2 & L3 & L4 & L5 \\
\hline Value $(\mathrm{mm})$ & 18 & 36 & 10 & 0.8 & 13.3 & 12 \\
\hline
\end{tabular}

\section{ANTENNA CONFIGURATION AND ANALYSIS}

\section{A. Proposed antenna}

All antenna parameters affect the antenna performance in terms of frequency response, efficiency, maximum gain, etc. However, this part presents in short the antenna reflection coefficient results by tuning only the main antenna parameters $\mathrm{L} 3, \mathrm{~W} 5, \mathrm{~W} 2$, and $\mathrm{R}$.

The reflection coefficient of the proposed Low-UWB antenna by varying $\mathrm{L} 3$, is presented in Fig. 2. It is clearly shown that, increasing L3 from 0.4 to $1.2 \mathrm{~mm}$ with a step of $0.4 \mathrm{~mm}$ results in broadening the $-10 \mathrm{~dB}$ bandwidth, particularly increasing the upper frequency from 4.25 to $4.73 \mathrm{GHz}$, while the low frequency remains constant at 3.62 GHz. Besides, results show that L3 parameter affect significantly to the resonance frequency and, hence the maximum achieved reflection coefficient. On the other hand, from the different reflection coefficient plots, it seems that another resonance could occur at $2 \mathrm{GHz}$ with the $\mathrm{L} 3$ value shift. The optimized $\mathrm{L} 3$ value is chosen to be $0.8 \mathrm{~mm}$.

The reflection coefficient of the proposed Low-UWB antenna by varying W5 is shown in Fig. 3. Results show that the resonance frequency remains the same at $4 \mathrm{GHz}$ by shifting W5 parameter. Decreasing W5 parameter from 20 to $18 \mathrm{~mm}$ with a step of $1 \mathrm{~mm}$, result in an increase in the maximum reflection coefficient from $-40.4 \mathrm{~dB}$ to $-16.6 \mathrm{~dB}$.

At the lower frequency a slight shift is obtained with an average value of $2.65 \mathrm{GHz}$, while at the upper frequency a significant increase is resulted from 4.42 to $4.73 \mathrm{GHz}$.

The reflection coefficient of the proposed Low-UWB antenna by varying W2 parameter is plotted in Fig. 4. W2 tune, from 17 to $18 \mathrm{~mm}$ with $0.5 \mathrm{~mm}$ step, can be considered one evidence to present general idea about the ground plane size effect on the antenna behavior/performances. Results show that the ground plane width has no effect either on the bandwidth [3.62-4.73 GHz] or on the resonant frequency $4 \mathrm{GHz}$. The optimized W2 value is chosen to be $17.5 \mathrm{~mm}$.
The reflection coefficient of the proposed Low-UWB antenna by varying $R$ is shown in Fig. 5. Results show that a slight increase of R parameter from 10.5 to $11.5 \mathrm{~mm}$ with a step of $0.5 \mathrm{~mm}$ result in a slight shift to the left of the frequency response, with a bandwidth and resonant frequency of $[3.62-4.73 \mathrm{GHz}]$ and $4 \mathrm{GHz}$, respectively. Finally, the ideal antenna bandwidth is $[3.62-4.73 \mathrm{GHz}]$ with the resonance frequency at $4 \mathrm{GHz}$ of $-40.36 \mathrm{~dB}$ is obtained with the accurate parameter values of $0.8,18$ 17.5, and $11.5 \mathrm{~mm}$ for $\mathrm{L} 3, \mathrm{~W} 5, \mathrm{~W} 2$ and $\mathrm{R}$ parameters. The achieved bandwidth covers the required one [3.754.25 GHz] in compliance with IEEE 802.15.6 standard.

The input impedance of the proposed Low-UWB antenna at $4 \mathrm{GHz}$ extracting the real and imaginary part is depicted in Fig. 6. At $4 \mathrm{GHz}$, the antenna proves a good impedance matching, since the real part of the input impedance is $50.21 \simeq 50 \Omega$ and the imaginary part is $-0.31 \simeq 0 \Omega$. Surface current distribution of the proposed Low-UWB antenna is illustrated in Fig. 7. Dense current is concentrated on the radiating element edge.

The proposed Low-UWB antenna reaches maximum gain up to $3.25 \mathrm{dBi}$ over the bandwidth $[3.62-4.73 \mathrm{GHz}$ in question. Relevant maximum gain values at 3.62, 4 and $4.73 \mathrm{GHz}$ are $2.85,3$ and $3.25 \mathrm{dBi}$, respectively, as demonstrated in Fig. 8 (a). Radiation and total efficiencies

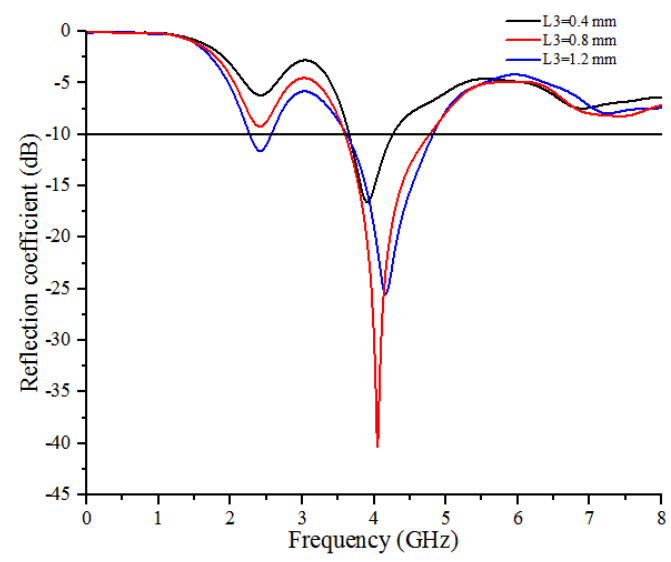

Fig. 2. Reflection coefficient of the proposed Low-UWB antenna by varying L3.

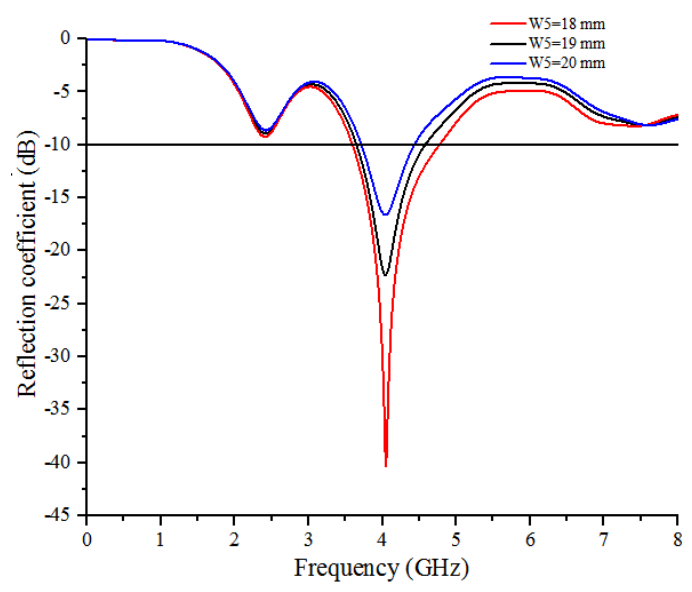

Fig. 3. Reflection coefficient of the proposed Low-UWB antenna by varying W5. 
are plotted in Fig. 8 (b), both result parameters are below $1 \mathrm{~dB}$ over the studied bandwidth. Therefore, it is concluded that the proposed antenna radiates well in the frequency range of interest [3.6-4.6 GHz].

Maximum directivity and gain values of the proposed Low-UWB antenna at different frequencies are shown in Table II and III, respectively. The antenna has an omnidirectional radiation pattern toward $\mathrm{Y}$-axis, corresponding to a monopole kind of radiation, with maximum directivity of $3.04,3.25,3.12,3.06$ and $3.66 \mathrm{dBi}$ at $3.62,3.75,4,4.25$ and $3.73 \mathrm{GHz}$, respectively. The radiation pattern of the proposed Low-UWB antenna at the previously listed frequencies according to different cuts (Theta $=90^{\circ}, \mathrm{Phi}=90^{\circ}, \mathrm{Phi}=0^{\circ}$ ) are plotted in Fig. 9.

\section{B. Cavity-backed approach}

The present section presents the proposed Low-UWB antenna using the cavity-backed approach as illustrated in Fig. 10. The air cavity presents an efficientsolution to enhance the antenna gain by $5.5 \mathrm{dBi}$ compared to a monopole presented in Section III A. Furthermore, radiation pattern is strived to change the behavior from omnidirectional to directional. The overall dimensions of the cavity are $96 \times 94 \times 51.6 \mathrm{~mm}^{3}$ corresponding to $1.28 \lambda \times 1.25 \lambda \times 0.69 \lambda$ (with $\lambda$ is the wavelength at $4 \mathrm{GHz}$ ). The ideal antenna position inside the cavity is in the center with $\mathrm{X}=30 \mathrm{~mm}, \quad \mathrm{Y} 1=35 \mathrm{~mm}, \quad \mathrm{Y} 2=25 \mathrm{~mm}, \quad$ and $\mathrm{Z} 1=\mathrm{Z} 2=25 \mathrm{~mm}$.

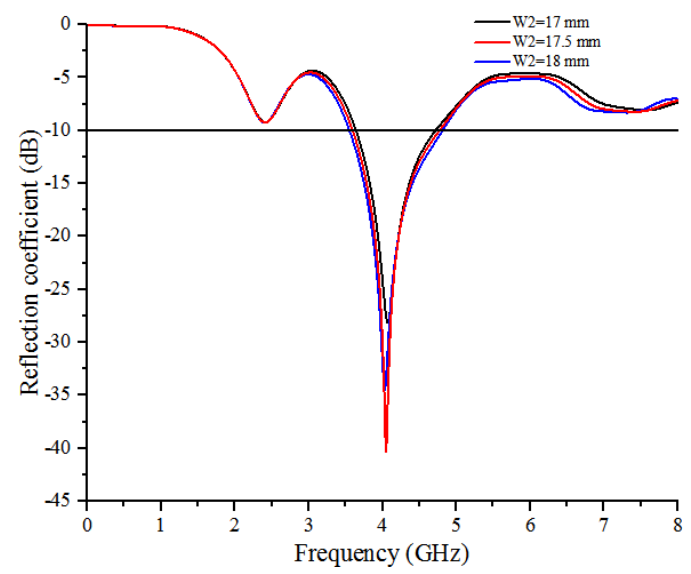

Fig. 4. Reflection coefficient of the proposed Low-UWB antenna by varying $\mathrm{W} 2$.

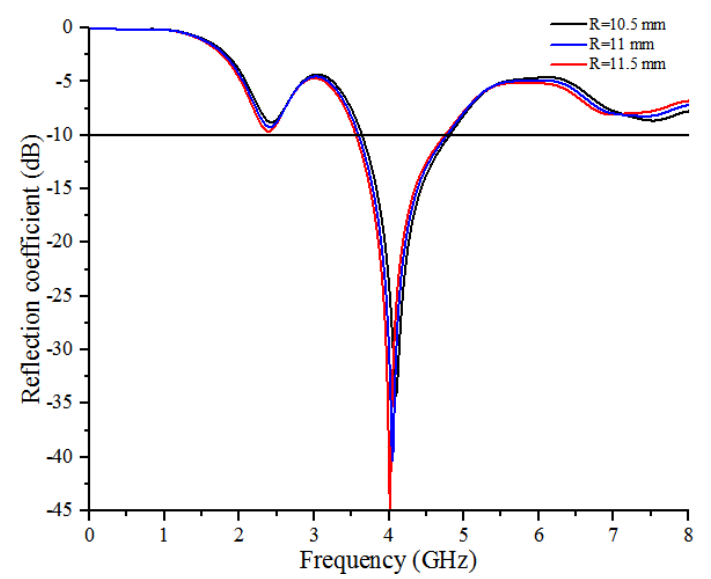

Fig. 5. Reflection coefficient of the proposed Low-UWB antenna by varying $R$.

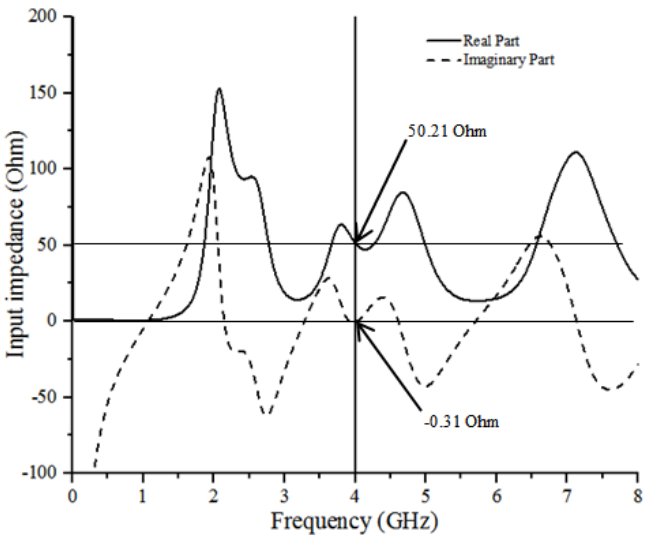

Fig. 6. Real and Imaginary part of the input impedance for the proposed Low-UWB antenna at $4 \mathrm{GHz}$.

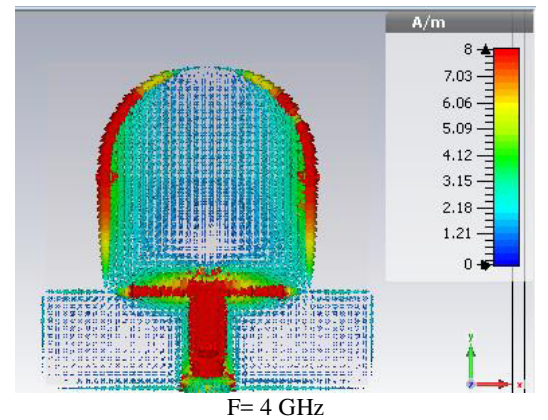

Fig. 7. Surface current distribution of the proposed Low-UWB antenna at $4 \mathrm{GHz}$.

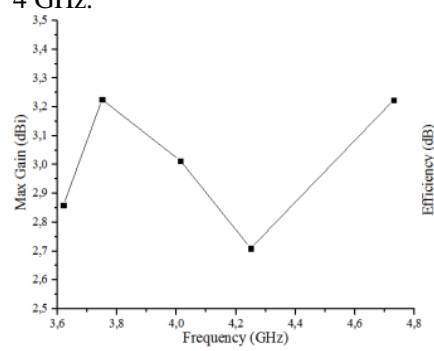

(a)

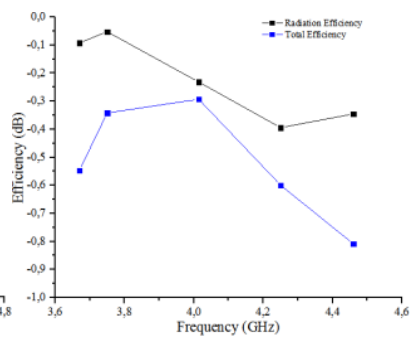

(b)
Fig. 8. (a) Maximum gain values and (b) Radiation and Total efficiency of the proposed Low-UWB antenna over the bandwidth frequencies.

All cavity parameters affect somehow the proposed antenna performances in terms of frequency response, efficiency and maximum achieved gain, etc. However, this section investigates in short the cavity-backed antenna behavior (reflection coefficient result parameter) by tuning only the main significant cavity parameters Z1, Y1 and X.

The reflection coefficient of the proposed Low-UWB cavity-backed antenna by varying Z1 is studied in Fig. 11. Results show that an increase of Z1 parameter from 12.5 to $25 \mathrm{~mm}$ by a step of $6.25 \mathrm{~mm}$ result in a significant increase in the maximum reflection coefficient from -14.2 to $49.9 \mathrm{~dB}$. Besides that, bandwidth is broadened with the increase of Z1 from 12.5 to $25 \mathrm{~mm}$ with bandwidths of [3.8$5 \mathrm{GHz}]$ and [3.49-5.7 GHz], respectively. On the other hand, it seems from the Fig. 13 that $\mathrm{Z1}$ parameter affects to the appearance of the undesired frequency occurred at $2 \mathrm{GHz}$. Therefore, by tuning accurately $\mathrm{Z1}$ parameter value, will lead to the cancellation of this undesired frequency. The optimized Z1 value is chosen to be $25 \mathrm{~mm}$.

The reflection coefficient of the proposed Low-UWB cavity-backed antenna by varying $\mathrm{Y} 1$ is investigated in Fig. 12. Results show that increasing the parameter Y1 from 
25 to $35 \mathrm{~mm}$ result in a slight shift in the low frequency from 3.6 to $3.49 \mathrm{GHz}$, while high frequency is increased from 5.1 to $5.7 \mathrm{GHz}$. Optimized Y1 value is chosen to be $35 \mathrm{~mm}$.

The reflection coefficient of the proposed Low-UWB cavity-backed antenna by varying $\mathrm{X}$ is presented in Fig. 13. Results show that tuning $\mathrm{X}$ parameter has no effect on the low frequency, however high frequency is sensitive to this parameter. Furthermore, by raising the parameter $\mathrm{X}$ the maximum reflection coefficient significantly increases from -30 to $-49.9 \mathrm{~dB}$.
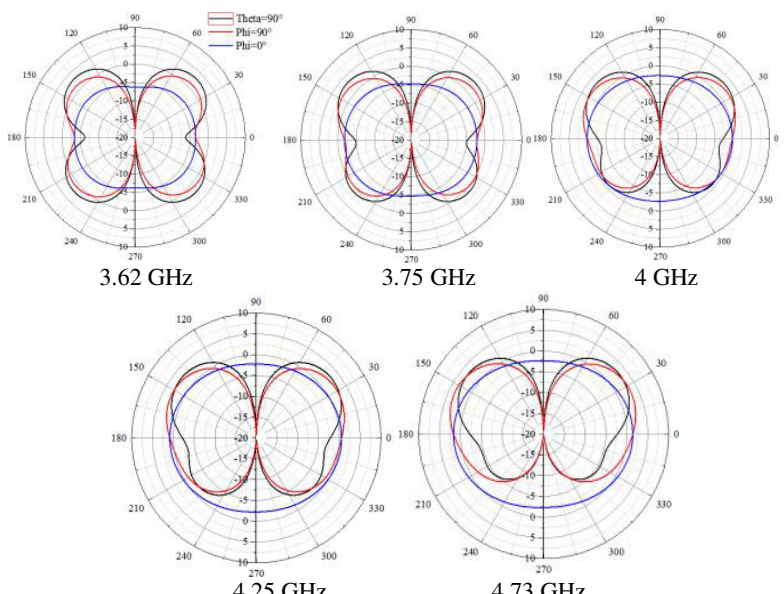

Fig. 9. Radiation patterns of the proposed Low-UWB antenna at 3.62, 3.75, $4,4.25$ and $4.73 \mathrm{GHz}$ in dBi. (Black $=>$ Theta $=90^{\circ}$, Red $=>P h i=90^{\circ}$ and Blue $=>$ Phi $=0^{\circ}$ )

TABLE II. MAXIMUM DIRECTIVITY VALUES BY DIFFERENT CUTS OF THE PROPOSED LOW-UWB ANTENNA

\begin{tabular}{ccccc}
\hline $\begin{array}{c}\text { Frequency } \\
(\mathbf{G H z})\end{array}$ & $\begin{array}{c}\mathbf{T h e t a}^{2} \mathbf{9 0}^{\circ} \\
(\mathbf{d B i})\end{array}$ & $\begin{array}{c}\mathbf{P h i}=\mathbf{9 0} \\
(\mathbf{d B i})\end{array}$ & $\begin{array}{c}\mathbf{P h i}^{\circ} \mathbf{0}^{\circ} \\
(\mathbf{d B i})\end{array}$ & $\begin{array}{c}\text { Max } \\
\text { Directivity } \\
(\mathbf{d B i})\end{array}$ \\
\hline $\mathbf{3 . 6 2}$ & 3.06 & 1.49 & -3.16 & 3.04 \\
$\mathbf{3 . 7 5}$ & 3.26 & 2.17 & -1.67 & 3.25 \\
$\mathbf{4}$ & 3.12 & 2.74 & 0.25 & 3.12 \\
$\mathbf{4 . 2 5}$ & 3.05 & 2.98 & 0.92 & 3.06 \\
$\mathbf{4 . 7 3}$ & 3.16 & 3.66 & 1.7 & 3.66 \\
\hline
\end{tabular}

TABLE III. MAXIMUM GAIN VALUES BY DIFFERENT CUTS OF THE PROPOSED LOW-UWB ANTENNA

\begin{tabular}{ccccc}
$\begin{array}{c}\text { Frequency } \\
(\mathbf{G H z})\end{array}$ & $\begin{array}{c}\mathbf{T h e t a}=\mathbf{9 0}^{\circ} \\
(\mathbf{d B i})\end{array}$ & $\begin{array}{c}\mathbf{P h i}^{\prime}=\mathbf{9 0}^{\circ} \\
(\mathbf{d B i})\end{array}$ & $\begin{array}{c}\mathbf{P h i}^{\circ} \mathbf{0} \\
(\mathbf{d B i})\end{array}$ & $\begin{array}{c}\text { Max Gain } \\
(\mathbf{d B})\end{array}$ \\
\hline $\mathbf{3 . 6 2}$ & 2.53 & 0.95 & -3.69 & 2.51 \\
$\mathbf{3 . 7 5}$ & 3.08 & 2 & -1.85 & 3.07 \\
$\mathbf{4}$ & 2.98 & 2.6 & 0.11 & 2.98 \\
$\mathbf{4 . 2 5}$ & 2.6 & 2.53 & 0.48 & 2.61 \\
$\mathbf{4 . 7 3}$ & 2.39 & 2.89 & 0.92 & 2.89 \\
\hline
\end{tabular}

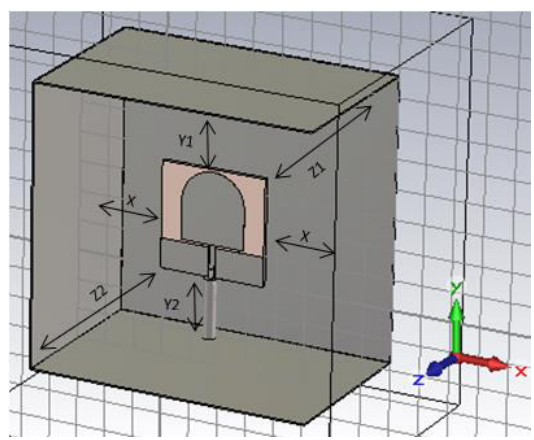

Fig. 10. Geometry of the proposed Low-UWB cavity-backed antenna.

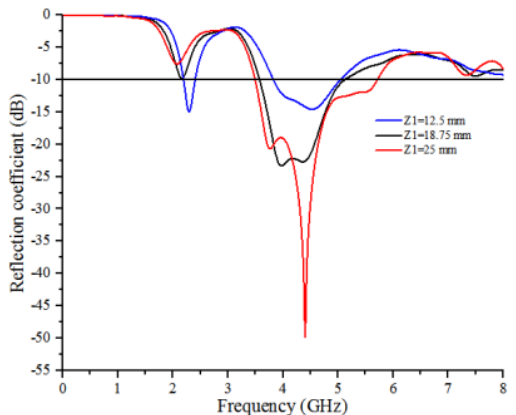

Fig. 11. Reflection coefficient of the proposed Low-UWB cavity-backed antenna by varying $\mathrm{Z} 1$.

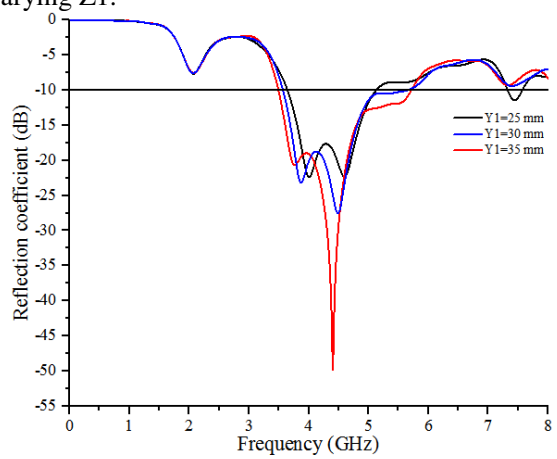

Fig. 12. Reflection coefficient of the proposed Low-UWB cavity-backed antenna by varying $\mathrm{Y} 1$.

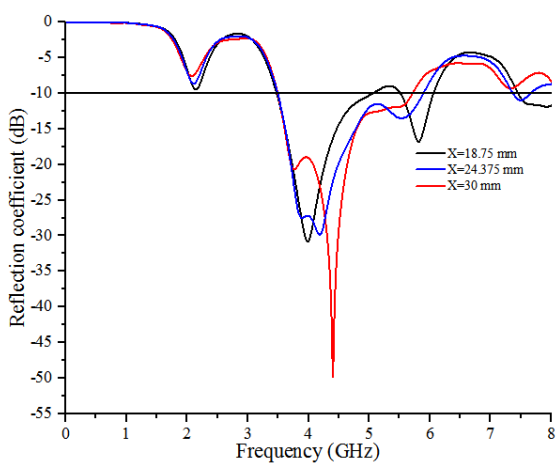

Fig. 13. Reflection coefficient of the proposed Low-UWB cavity-backed antenna by varying $X$.

Finally, the ideal antenna bandwidth is [3.49-5.7 GHz] with the resonance frequency at $4.4 \mathrm{GHz}$ of $-49.9 \mathrm{~dB}$ is obtained with the accurate cavity parameter values of 25 , 35 , and $30 \mathrm{~mm}$ for $\mathrm{Z} 1, \mathrm{Y} 1$, and X parameters. The achieved bandwidth covers the required one $[3.75-4.25 \mathrm{GHz}]$ in compliance with IEEE 802.15.6 standard.

The proposed Low-UWB cavity backed antenna reaches maximum gain of $10 \mathrm{dBi}$ at $5.7 \mathrm{GHz}$. As demonstrated in Fig. 14 (a), the maximum gain values at 3.75, 4 and $4.25 \mathrm{GHz}$ are 7.5, 8.5 and $7.75 \mathrm{dBi}$, respectively. Radiation and total efficiencies are plotted in Fig. 14 (b), both result parameters are better than $-1 \mathrm{~dB}$ over the studied bandwidth. Therefore, it is concluded that the proposed Low-UWB cavity-backed antenna radiates well in the frequency range of interest [3.49-5.7 GHz]. The angular $3 \mathrm{~dB}$ width for const $\mathrm{Phi}=0^{\circ}$ over the bandwidth in question is presented in Fig. 14 (a). At $4 \mathrm{GHz}$, an angular $3 \mathrm{~dB}$ width of around $43 \mathrm{deg}$ is shown.

Maximum directivity and gain values of the proposed Low-UWB cavity-backed antenna at different frequencies are shown in Table IV and V, respectively. The proposed 


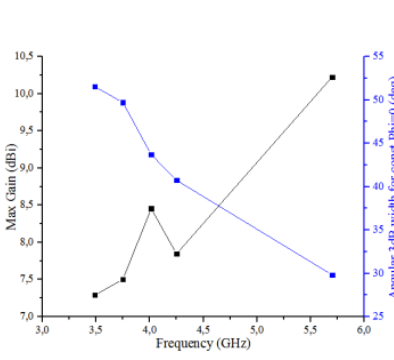

(a)

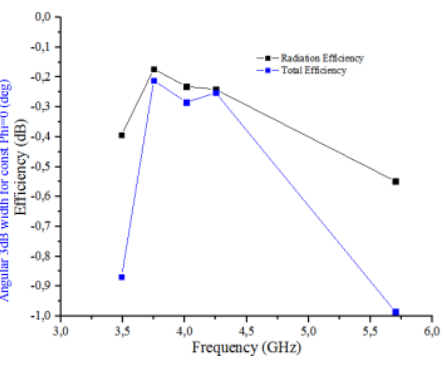

(b)
Fig. 14. (a) Maximum gain and angular $3 \mathrm{~dB}$ width for const Phi=0 and (b) Radiation and Total efficiency of the proposed Low-UWB cavity-backed antenna over the bandwidth frequencies.

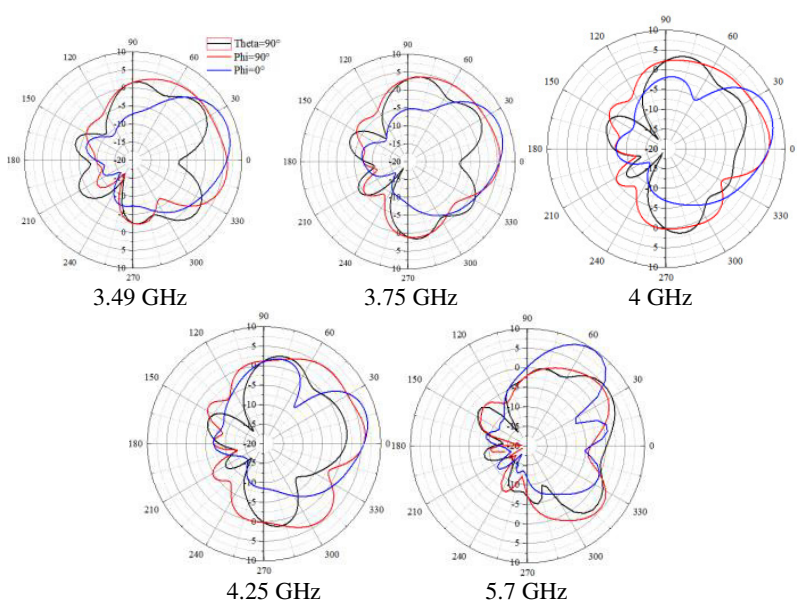

Fig. 15. Radiation patterns of the proposed Low-UWB cavity-backed antenna at $3.62,3.75,4,4.25$ and $4.73 \mathrm{GHz}$ in $\mathrm{dBi}$. (Black $=>$ Theta $=90^{\circ}$, Red $=>$ Phi $=90^{\circ}$ and Blue $=>$ Phi $=0^{\circ}$ )

TABLE IV. MAX DIRECTIVITY VALUES BY DIFFERENT CUTS OF THE PROPOSED LOW-UWB CAVITY-BACKED ANTENNA

\begin{tabular}{ccccc}
\hline $\begin{array}{c}\text { Frequency } \\
(\mathbf{G H z})\end{array}$ & $\begin{array}{c}\mathbf{T h e t a = 9 0}^{\circ} \\
(\mathbf{d B i})\end{array}$ & $\begin{array}{c}\mathbf{P h i}^{\circ} \mathbf{9 0} \\
(\mathbf{d B i})\end{array}$ & $\begin{array}{c}\mathbf{P h i}^{\circ} \\
(\mathbf{d B i})\end{array}$ & $\begin{array}{c}\text { Max } \\
\text { Directivity } \\
(\mathbf{d B i})\end{array}$ \\
\hline $\mathbf{3 . 4 9}$ & 4.07 & 6.19 & 7.67 & 7.68 \\
$\mathbf{3 . 7 5}$ & 3.91 & 5.77 & 7.4 & 7.67 \\
$\mathbf{4}$ & 3.86 & 6.25 & 7.82 & 8.68 \\
$\mathbf{4 . 2 5}$ & 2.9 & 6.14 & 7.3 & 8.09 \\
$\mathbf{5 . 7}$ & 5.11 & 4.69 & 9.86 & 10.8 \\
\hline
\end{tabular}

TABLE V. MAX GAIN VALUES BY DIFFERENT CUTS OF THE PROPOSED LOW-UWB CAVITY-BACKED ANTENNA

\begin{tabular}{ccccc}
\hline $\begin{array}{c}\text { Frequency } \\
(\mathbf{G H z})\end{array}$ & $\begin{array}{c}\mathbf{T h e t a}^{\prime}=\mathbf{9 0}^{\circ} \\
(\mathbf{d B})\end{array}$ & $\begin{array}{c}\mathbf{P h i}^{\circ} \mathbf{9 0}{ }^{\circ} \\
(\mathbf{d B})\end{array}$ & $\begin{array}{c}\mathbf{P h i}^{\circ} \\
(\mathbf{d B})\end{array}$ & $\begin{array}{c}\text { Max } \\
\text { Gain } \\
(\mathbf{d B})\end{array}$ \\
\hline $\mathbf{3 . 4 9}$ & 3.18 & 5.3 & 6.8 & 6.82 \\
$\mathbf{3 . 7 5}$ & 3.7 & 5.56 & 7.19 & 7.46 \\
$\mathbf{4}$ & 3.58 & 5.95 & 7.52 & 8.4 \\
$\mathbf{4 . 2 5}$ & 2.64 & 5.84 & 7.03 & 7.83 \\
$\mathbf{5 . 7}$ & 4.12 & 3.69 & 8.88 & 9.79 \\
\hline
\end{tabular}

antenna has a directional radiation pattern toward $\mathrm{Z}$-axis with maximum directivity values of $7.68,7.67,8.68,8.09$ and $10.8 \mathrm{dBi}$ at $3.49,3.75,4,4.25$ and $5.7 \mathrm{GHz}$, respectively. The radiation pattern of the proposed LowUWB antenna at the previously listed frequencies according to different cuts Theta $=90^{\circ}$, $\mathrm{Phi}=90^{\circ}$ and $\mathrm{Phi}=0^{\circ}$ are plotted in Fig. 15.

\section{CONCLUSION AND PERSPECTIVES}

This paper presents a new Low-UWB antenna providing directional and omnidirectional radiation patterns with and without the cavity approach, respectively. Both antenna approaches cover IEEE 802.15.6 standard requirements in terms of $-10 \mathrm{~dB}$ impedance matching for (Body Area Network Part) which includes $4 \mathrm{GHz}$ center frequency and bandwidth about [3.75-4.25 GHz]. The cavity was introduced to enhance the gain and provide more directivity of the proposed antenna. Besides, it has broadened the required bandwidth up to $5.7 \mathrm{GHz}$ which can be good to assess the antenna behavior for relatively higher frequencies. Further investigations are planned as following steps based on realistic human models, with fabrication and test process. The present investigation study proves that the proposed antenna can be considered a good candidate for Low-UWB applications for example for Wireless Capsule Endoscopy Localization that requires the design of a high gain and directive receiving antenna.

\section{REFERENCES}

[1] E. Schires; P. Georgiou; and T. S. Lande, "Vital Sign Monitoring Through the Back Using an UWB Impulse Radar With Body Coupled Antennas", IEEE Transactions on Biomedical Circuits and Systems, vol. 12 , pp. $292-302,2018$

[2] A. Alemaryeen; S. Noghanian; and R. F-. Rezai, "Antenna Effects on Respiratory Rate Measurement using a UWB Radar System", IEEE Journal of Electromagnetics, RF and Microwaves in Medicine and Biology, vol. 2, pp. $87-93,2018$.

[3] A. Ahmed; Y. Zhang; D. Burns; D. Huston; and T. Xia, "Design of UWB Antenna for Air-Coupled Impulse Ground-Penetrating Radar", IEEE Geoscience and Remote Sensing Letters, vol. 13, pp. 92 - 96, 2016.

[4] J. Shi; J. Wang, "Channel Characterization and Diversity Feasibility for In-Body to On-Body Communication using Low-band UWB Signals", 3rd International Symposium on Applied Sciences in Biomedical and Communication Technologies (ISABEL 2010), pp. 1 4, 2010

[5] 5. K. M. S. Thotahewa; J. -M. Redoutè; M. R. Yuce, "Propagation, Power Absorption, and Temperature Analysis of UWB Wireless Capsule Endoscopy Devices Operating in the Human Body", IEEE Transactions on Microwave Theory and Techniques, vol. 63, pp. 3823 $-3833,2015$.

[6] IEEE Standard for Local and metropolitan area networks _Part 15.6: Wireless Body Area Networks, pp. IEEE Std 802.15.6-2012, pp. 1 271, 2012.

[7] S-. G. Zhou; and J-. Y. Li, "Low-Profile and Wideband Antenna", IEEE Antennas and Wireless Propagation Letters, vol. 10, pp. 373 376, 2011.

[8] Z. Wang; J. Wu; Y. Yin; and X. Liu, "A Broadband Dual-Element Folded Dipole Antenna With a Reflector", IEEE Antennas and Wireless Propagation Letters, vol. 13, pp. 750 - 753, 2014.

[9] C. R. P-. Ojeda; M. C-. Fabrés; E. A-. Daviu; and M. F-. Bataller, "Design of an Unidirectional UWB Cavity Backed Antenna", IEEE MTT-S International Conference on Numerical Electromagnetic and Multiphysics Modeling and Optimization for RF, Microwave, and Terahertz Applications (NEMO), pp.28 - 30, 2017.

[10] A. Munir; and R. B. V. B. Simorangkir, "Performance Enhancement of Cavity-backed UWB Printed Monopole Antenna”, IEEE Asia Pacific Microwave Conference (APMC), pp. 584 - 587, 2017.

[11] E. Merkley; B. Jackson; C. Saavedra; and Y. Antar, "A Compact Cavity-Backed Monopole Antenna For UWB Applications", IEEE International Symposium on Antennas and Propagation \& USNC/URSI National Radio Science Meeting, pp. 495 - 496, 2017.

[12] D. Awan; S. Bashir; and W. Whittow, "High Gain Cavity Backed UWB Antenna with and Without Band Notch Feature", Loughborough Antennas \& Propagation Conference (LAPC), pp. $299-302,2013$.

[13] J. M-. Vargas; R. A. R-. Solís; M. A. Elmansouri; and D. S. Filipovic, "A UWB Cavity-Backed Compound Power-Archimedean Slot Spiral for Body Centric Wireless Communications Applications", IEEE International Symposium on Antennas and Propagation \& 
USNC/URSI National Radio Science Meeting, pp. 1978-1979, 2015.

[14] Q. V. d. Brande; S. Lemey; J. Vanfleteren; and Hendrik Rogier, "Highly-Efficient Impulse-Radio Ultra-Wideband Cavity-Backed Slot Antenna in Stacked Air-Filled Substrate-Integrated-Waveguide Technology", IEEE Transactions on Antennas and Propagation, vol. 66, pp. 2199-2209, 2018.

[15] A. Ali; M. Hamza; and W. T. Khan, "Smallest Form Factor, High Performance 2-18 GHz Cavity-Backed Archimedean Spiral Antenna", International Symposium on Antennas and Propagation (ISAP), pp. 1-2, 2017.

[16] R. Ferreira; J. Joubert; and J. W. Odendaal, "A compact dualcircularly polarized cavity-backed ring-slot antenna", IEEE Transactions on Antennas and Propagation, vol. 65, pp. $364-368$, 2017.
[17] A. Munir; R. B. V. B. Simorangkir; and F. Kurniawan, "Late-time Ringing Characterization of Cavity-Backed UWB Printed Monopole Antenna", IEEE Conference on Antenna Measurements \& Applications (CAMA), pp. $419-422,2017$.

[18] J-. Y. Li; R. Xu; X. Zhang; S-. G. Zhou; and G-. W. Yang, "A Wideband High-Gain Cavity-Backed Low-Profile Dipole Antenna", IEEE Transactions on Antennas and Propagation, vol. 64, pp. 5465 $5469,2016$.

[19] E. L-. Arzate; J. A. T-. Mendez; J. C-. Franca ; R. F-. Leal ; H. J-. Aguilar; M. A. P-. Solis, "Ultra-wideband directive antenna based on an inclined cone body", IET Microwaves, An-tennas\& Propagation, vol. 12, pp. 339-345, 2018. 